\title{
Prolonged remission in Di Guglielmo's syndrome
}

\author{
R. CARR* \\ B.Sc., M.B., Ch.B., M.R.C.P. \\ E. M. INNES \\ M.B., Ch.B., F.R.C.P.Ed \\ Department of Haematology, Royal Hospital for Sick Children, \\ Sciennes Road, Edinburgh EH9 ILF
}

\begin{abstract}
Summary
A case is reported of a 12-year-old boy with $\mathrm{Di}$ Guglielmo's syndrome who achieved complete remission for over three years before developing a central nervous system relapse. The poor results of treatment in this disease are reviewed and the arguments for routine central nervous system prophylaxis discussed.
\end{abstract}

KEY WORDS: erythroleukaemia, CNS prophylaxis.

\section{Introduction}

Di Guglielmo's syndrome or erythroleukaemia is an uncommon form of acute non-lymphocytic leukaemia. While the syndrome accounts for up to $10 \%$ of adult acute leukaemias, it represents only $1 \%$ of all cases of leukaemia in childhood (Pierce et al., 1969). Until recently Di Guglielmo's syndrome was thought to be refractory to chemotherapy in most instances. A case is reported of a 12-year-old boy who achieved complete remission for over three years before developing central nervous system (CNS) relapse.

\section{Case report}

A previously healthy 12-year-old boy presented with a two week history of progressive pallor and tiredness. On examination there was no lymphadenopathy or hepatosplenomegaly. Peripheral blood examination showed a haemoglobin $3.9 \mathrm{~g} / \mathrm{dl}$, platelets $120 \times 10^{9} /$ litre, total white cell (WBC) count of $2.6 \times 10^{9} /$ litre (neutrophils $38 \%$, lymphocytes $55 \%$, blasts $7 \%$ ) and five nucleated red cells per $100 \mathrm{WBC}$. The blast cells had primitive nuclei with abundant, deeply basophilic cytoplasm almost entirely occupied by large round vacuoles. The bone marrow aspirate showed $31 \%$ of cells to be erythroblasts displaying grossly megaloblastic maturation, some having bi-

\footnotetext{
*Present address: Dept. of Haematology, Royal Infirmary, Lauriston Place, Edinburgh.
}

zarre clover-leaf nuclei, and diffuse PAS positives cytoplasm. There were many ring sideroblasts.

Fifty-six percent of cells were blast cells, identicat to those seen in the peripheral blood (Fig. 1). These were PAS negative and Sudan Black positive. Aues rods were absent. Serum $B_{12}$ and folate were normaL These features have previously been described characteristic of Di Guglielmo's syndrome (Dam? eshek, 1969; Scott, Ellison and Ley, 1964; Sonder gaard-Petersen, 1975a). The appearance of the vacuolated blast cells is unusual but has been previousl 18 reported in erythroleukaemia (Miura, 1976).

The patient was commenced on chemothergipg with thioguanine, daunorubicin, cytosine arabinoside and prednisolone, as described by Spiers (1972 Chemotherapy was repeated at two weekly intervaly for six courses; adriamycin was then substituted fo daunorubicin and the treatment interval extended to 3 weeks. Complete remission with an entirely norma bone marrow was achieved at 23 weeks. After fourteen courses, chemotherapy was changed to 沜 maintenance regime of cytosine arabinoside and thioguanine for 5 days, repeated every 3 weeks. At 39 weeks lumbar puncture was performed. The ceres brospinal fluid (CSF) was clear with no cells. Si intrathecal injections of cytosine arabinoside $50 \mathrm{mg}$ were given at three weekly intervals as CNS prophy3 laxis. All chemotherapy was discontinued 2 years after diagnosis, the patient being well and in com? plete remission.

Fourteen months after ceasing chemotherapy he presented with headaches, vomiting and two convulos sions. His CSF now contained blast cells, identical to those in the marrow at diagnosis (Fig. 2). The CNS relapse has been successfully treated with craniosp nal irradiation and further intrathecal chemotherap using cytosine arabinoside and methotrexate. He was also given a short course of systemic chemotherapyed His CSF remains cell-free one year later. His bone marrow has remained in complete remissiob throughout. 

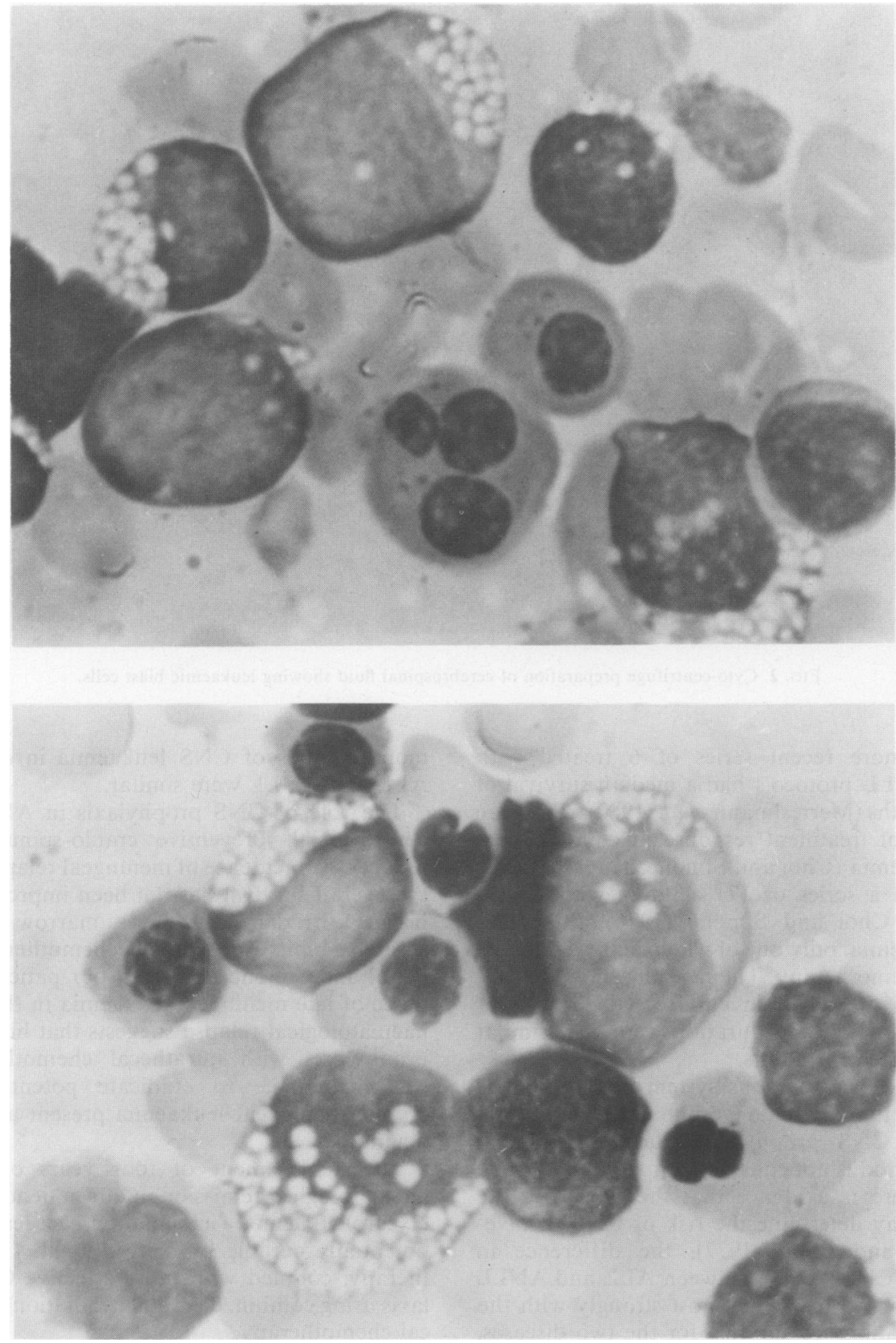

FIG. 1. Two fields from the bone marrow at presentation (Stain-May-Grunwald Giemsa) showing vacuolated leukaemic blast cells and dyserythropoietic erythroblasts. Note erythroblast with three nuclei.

\section{Discussion}

While newer chemotherapy regimes have improved survival in most categories of acute nonlymphocytic leukaemia (ANLL) over the past dec- ade, erythroleukaemia has remained relatively refractory to treatment. In a series of 17 cases of adult erythroleukaemia reported in 1975 the longest survivor died at 20 months (Sondergaard-Petersen, 


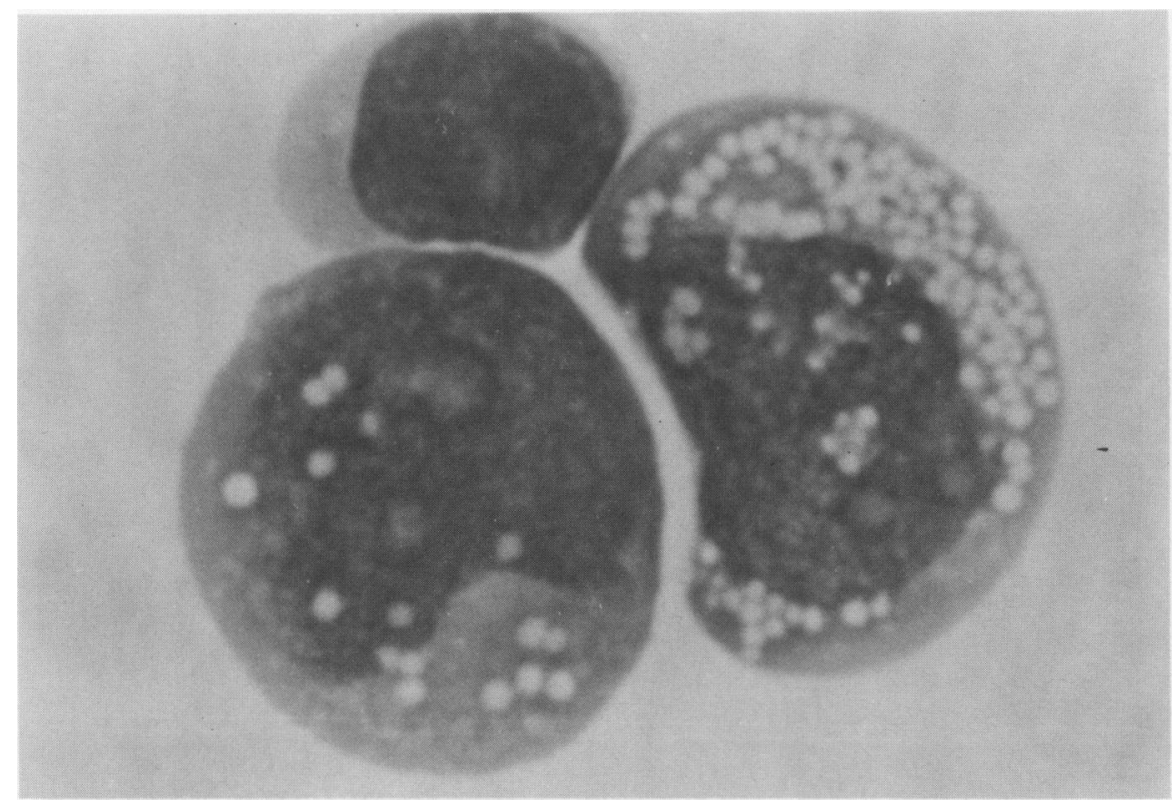

FIG. 2. Cyto-centrifuge preparation of cerebrospinal fluid showing leukaemic blast cells.

1975a). A more recent series of 6 treated with standard ANLL protocols had a median survival of only 5.6 months (Merteslmann et al., 1980). There are few reports of treatment response in children with erythroleukaemia (Choi and Simone, 1976; Ragab et al., 1975). In a series of 171 children with ANLL reported by Choi and Simone (1976), three had erythroleukaemia, only one of whum achieved remission with chemotherapy. Their results show that for all categories of ANLL in children, the results of remission induction and duration were very similar to those reported for adults.

In ANLL central nervous system involvement is less common than in acute lymphoblastic leukaemia (ALL) and CNS prophylaxis during the initial treatment period is not considered mandatory. While in adults there is evidence that the type of acute leukaemia may determine the risk of CNS involvement (Law and Blom, 1977), the difference in frequency of CNS relapse between ALL and ANLL has been shown to correlate most strongly with the different durations of survival for the two diseases, regardless of the age of the patient (Wolk et al., 1974; Evans, Gilbert and Zandstra, 1970). The overall frequency of CNS leukaemia in children who have not been given CNS prophylaxis is $56-83 \%$ for ALL (Evans et al., 1970; Pinkel et al., 1971) and 25-38\% for all categories of ANLL (Evans et al., 1970; Choi and Simone, 1976). However, Evans et al. (1970) found that over the first twelve months from diagnosis the monthly rates of CNS leukaemia in children with ALL and ANLL were similar.

The role of CNS prophylaxis in ANLL remains controversial. Preventive cranio-spinal irradiation 5 reduces the incidence of meningeal relapse. However: the overall survival has not been improved, possibly because irradiation reduces marrow reserve and severely limits subsequent chemotherapy dosages? (Choi and Simone, 1976). In our patient the occur-5 rence of late meningeal leukaemia in the absence of haematological relapse suggests that his initial CNS prophylaxis with intrathecal chemotherapy alone was inadequate to eradicate potentially curables cryptic meningeal leukaemia present at the time of diagnosis.

The achievement of four years of continuous haematological remission in our patient suggests that erythroleukaemia, in children at least, may be potentially curable by conventional ANLL chemo: therapy, coupled with more effective CNS prophy laxis using combined cranial irradiation and intrathecal chemotherapy.

\section{References}

CHol, S.I. \& Simone, J.V. (1976) Acute non-lymphocytic leukaemia in 171 children. Medical \& Paediatric Oncology, 2, 119.

DAMESHEK, W. (1969) The Di Guglielmo syndrome revisited. Blood 34, 567.

Evans, A.E., GILBERT, E.S. \& ZANDSTRA, R. (1970) The increasing incidence of central nervous system leukaemia in childreno Cancer, 26, 404. 
LAW, I.P. \& BLOM, J. (1977) Adult acute leukaemia-Frequency of central nervous system involvement in long-term survivors. Cancer, 40, 1304.

Merteslmann, R., Thaler, T., To, L., Gee, T.S., McKenzie, S., Schauer, P., Friedman, A., Arlin, Z., Cirrincione, C. \& CLARKSON. B. (1980) Morphological classification. response to therapy and survival in 263 adult patients with acute nonlymphoblastic leukaemia. Blood, 56, 773.

MIURA, A.B. (1976) Multiple vacuole formation in erythroblasts in an erythroleukaemic patient. Scandinavian Journal of Haemato$\log v, 16,183$.

Pierce, M.I., Borges, W.H., Heyn, R., Wolff, J.A. \& Gilbert, E.S. (1969) Epidemiological factors and survival experience in 1770 children with acute leukaemia treated by members of Children's Cancer Study Group A. between 1957 and 1964. Cancer, 23, 1296.

Pinkel, D., Hernandez, K., Borella, L.. Holton. C., Aur. R.. SAMOY, G. \& PRATT, C. (1971) Drug dosage and remission duration in childhood lymphocytic leukaemia. Cancer. 27, 247.
Ragab, A.H., Sutow, W.W., Komp, D.M.. StaRling, K.A., Lyon, G.M. \& George. S. (1975) Adriamycin in the treatment of childhood acute leukaemia. Cancer, 36, 1223

SCOTt, R.B., Ellison, R.R. \& LEY, A.B. (1964) A clinical study of twenty cases of erythroleukaemia (Di Guglielmo's syndrome). American Journal of Medicine. 37, 162.

SONDERGAARD-PETERSEN. H. (1975a) Di Guglielmo's syndrome: A study of 17 cases. Part I: Clinical and haematological manifestations. Acta Medica Scandinavica. 198. 165.

SondergaARD-PETERSEN, H. (1975b) Di Guglielmo`s syndrome: a study of 17 cases. Part II: Periodic-acid-Schiff staining of the erythroblasts. Acta Medica Scandinavica. 198, 175.

SPIERS, A.S.D. (1972) Chemotherapy of acute leukaemia. Clinics in Haematology, 1, 127.

WOLK. R.W.. MASSE. R.. CONKLIN. R.\& Freireich. E.J. (1974) The incidence of central nervous system leukaemia in adults with acute leukaemia. Cancer. 33, 863 .

(Accepted 2 April 1982) 